\title{
THE ROYAL SOCIETY SCIENTIFIC INFORMATION CONFERENCE
}

\section{Introduction}

$\mathrm{T}$ HE Scientific Information Conference held by the Royal Society during June 21-July 2, which was attended by about a hundred and thirty delegates from organisations in the United Kingdom and thirty from the Overseas Commonwealth and the United States in addition to about a hundred observers, was the outcome of a recommendation passed by the Royal Society Empire Scientific Conference of 1946 to examine, in this way, the possibilities of improvement in existing methods of collection, indexing and distribution of scientific literature and of the extension of existing abstracting services.

The importance of the questions involved arises from the overwhelming mass of the literature, which is estimated to total anything up to one million published items a year, apart from the unpublished reports and memoranda which multiply within every scientific establishment and may locally be even more important. This makes it impossible for any individual to scan more than an infinitesimal fraction of what currently appears even within a limited field, or to be sure of finding retrospectively those references which are the most apposite to his own work, unless the indirect means of doing so are highly organised.

Various aspects of the problem have, over many years now, been receiving attention on behalf of the scientific worker through such bodies as ASLIB (a union of the Association of Special Libraries and Information Bureaux with the former British Society for International Bibliography), the International Federation for Documentation, the British Standards Institution and latterly the Technical Information Services Panel of the Committee on Industrial Productivity appointed by the Lord President of the Council. Much useful discussion is to be found in the published proceedings of the first two of these organisations; but along some lines of development-as, for example, mechanical methods of selecting literature references - the position reached is that inventors of machinery and documentary devices have progressed ahead of the ability of the users to tell them what they actually want done. Hence the value of a conference representing primarily the beneficiaries rather than the organisers of information services, and particularly of one at which the special problems that beset scientific men working at isolated posts overseas could receive their due share of attention.

The Conference was organised in four sections to appreciate and discuss what can be done to improve and rationalize the arrangements for :

(1) Publishing and distributing original scientific papers (Editor: Prof. J. D. Bernal).

(2) Issuing and using abstracts to convey current awareness of the availability and relevance of such papers (Editor: Sir David Chadwick).

(3) Consolidating abstracts or other forms of reference into continuously cumulative indexes and using these and other library services for the retrospective searching of the literature (Editor : Dr. J. E. Holmstrom).

(4) Producing and utilizing periodical reviews of progress in designated fields of science (Editor : Prof. H. Munro Fox).

The editors were appointed some months beforehand to take charge of each of the four sections, and they had, with assistance from others, prepared much material for consideration. Terms of reference had been drafted for forty-two specific subjects of study by sixteen working parties. At the opening plenary sessions of the Conference the background to these questions was explained by the editors and the membership of the working parties was made up, each consisting of six to eight persons having special knowledge of the groups of questions they were to answer. In some cases panels of consultants were also listed from which the working parties could co-opt additional members when considering particular questions. The working parties then met separately- $-x$ cept for a few joint meetings where the interests of several overlapped-until the final plenary sessions, when their conclusions and draft recommendations for action on each question were reported to the Conference as a whole for adoption, amendment or rejection. In this way altogether some seventy recommendations were finally sent forward by the Conference to the Royal Society, proposing positive actions either by the latter directly or through appropriate named organisations.

\section{Section 1: Publication and Distribution of Papers Reporting Original Work}

Section 1 of the Conference had to deal with the publication and distribution of papers containing reports of original work. Papers referring to this prepared for the Conference were essentially of two kinds: those setting out suggestions or expressing opinions, and those containing numerical and statis. tical information on publication and reading habits. In the first category were the group of papers on Prof. J. D. Bernal's proposed scheme for centralized distribution of scientific papers, criticisms of it by the Physical Society and by the editors of some biological societies, and comments on these views. In the second category were studies on the average length and scatter of papers in different periodicals, on the variety of formats in journals taken at the library of the Royal Botanic Gardens, Kew, on delays in publication; and lists were prepared, after consultation with societies, of the chief jourmals published in different fields in the United Kingdom and the Commonwealth.

In addition to these, the results of two surveys, one organised by Mr. Urquhart on papers inquired for at the Science Library, and the other of a special questionnaire sent out to research workers in Cambridge, the Department of Scientific and Industrial Research, Rothamsted Experimental Station, the Medical Research Council and various industrial firms. The steering committee of the Section eventually drew up a set of terms of reference for five working parties :

Working Party $I / A$ : (i) To examine the present format of scientific publications and to make recom. mendations as to the adoption of suggested standards. (ii) To review methods of reproduction of scientific papers and to make recommendations as to the applicability of each.

Working Party $I / B$ : To study the importance of editorial distribution and other factors in relation to the length of scientific communications and to make recommendations as to any desirable changes.

Working Party $I / C$ : To consider whether any advantage would be gained from a more rational 
subject grouping of scientific communications within existing journals.

Working Party $I / D$ : To consider the general question of the organisation for publication of original papers and the mechanism for their distribution, and to recommend any steps which may be taken through the co-operation of existing bodies towards achieving any desirable improvements.

Working Party $I / E$ : (i) To examine the present causes of delay in publishing original scientific work and to make recommendations. (ii) To review existing difficulties in the availability of scientific information to men of science, and to make recommendations.

In order, however, to give greater coherence to the work of the Section, the first and last meetings of 'working parties' were joint working parties, and joint meetings of working parties of different sections were arranged on the subjects of photographic reproduction methods and classification.

At the opening plenary session on June 21, with Sir Alfred Egerton in the chair, short statements were made by the editors and the leaders of the working parties and a general discussion followed, with the purpose of conveying to the 'working parties' the views of the members of the Conference. On June 23 there was a special plenary session to consider the replies to the questionnaire already referred to, and to another sent out by Sir David Chadwick on abstract services.

The major conclusions of the questionnaires were of a very decisive character and modified considerably the type of proposals put before the Conference. The most important of these results was that emphasizing the large reliance of research workers on libraries, principally departmental libraries, three-quarters of their reading being derived from this source and the relatively smell proportion of reading derived from journals subscribed to by the research workers themselves. It would appear that the average research worker looks through some nine papers a week and reads three carefully, making notes and usually keeping a card index. The paper was read, in 37 per cent of the cases, on account of a reference in another paper and only in 18 per cent on account of an abstract. Reprints furnished 6 per cent of the general reading, but 12 per cent of the careful reading. There were some significant differences between the reading habits of the different sections, those in the applied sciences reading on the whole fewer papers than their more academic fellow workers, and senior workers looking through more papers, but reading fewer carefully, than junior workers. The distribution of reading in various journals was significant : 2,000 papers described as carefully read during the course of the inquiry were derived from 430 different journals; but the distribution of papers consulted among journals varied enormously, onequarter of the papers being found in six journals, half in thirty, and the last quarter in 330 different journels. This emphasizes a law derived by Bradford from studies of the actual distribution in journals of papers covering particular topics, and shows that his conclusions apply equally strongly to papers actually read. It is also notable that more foreign papers were read than British, and that the great majority of these were American. The major conclusion that can be drawn from these results is that, in the absence of any rational system of distribution of papers by subject, the libraries are the essential agents in the distribution of scientific publications.
The 'working parties' each held a number of meetings which were on the whole remarkably free from controversy, and came to conclusions and recommendations for the most part unanimously. The position of working party I/A was fortunate in that its chairman, M. Lemaitre, had just returned from a meeting of the International Standards Organisation at Geneva and was able to refer the Conference to resolutions already taken on the standardizing of the format of periodicals. The advantage of a limited number of sizes was admitted, and the resolution passed that once these standards were accepted societies would be urged to adopt them whenever they were changing their format. Similar considerations were given to the layout, particularly on such questions as the form of reference and the desirability of beginning each separate paper on a right-hand page to facilitate the issue of reprints and the division of the journal into papers for reference purposes. On questions of reproduction, it was agreed for the most part that printing is the most suitable for large numbers, but that new methods, particularly lithography and the diazo reflex process, might be increasingly used when small numbers are required. The 'working party' put its weight behind the general recommendation for further research on, and development of, methods of reproduction.

'Working party I/B' was on much more controversial ground in its study of the lengths of papers. While there was general agreement that too many papers of a repetitive nature are written, and that papers are longer than they need bə, results incorporated in the general resolution of the Section, there was more discussion on the suggestion of extending the practice, already adopted by the Institution of Electrical Engineers and some other bodies, of issuing with the journal a full précis of a length from one-twentieth to one-quarter the original length of the paper, to be issued together as précis-journals covering a cognate group of sciences. The argument for such précisjournals was that they would provide digests of material lying outside the immediate field of any particular worker which would not, in fact, be read unless presented in this shortened form. The argument against it was that the proposal involved the issuing of still further publications and that the field would be covered as adequately by informative abstracts. The 'working party' finally agreed to put forward the suggestion for consideration by the proposed consultative committees of editors suggested by 'Working party I/C'. 'Working party I/B' further considered the need for making provision for the preservation and permanent availability on demand of copies of scientific documents and reports which are too long for publication in the ordinary way. It recommended that some system of deposit similar to that of the Science Service in the United States should be established.

'Working party I/C' was concerned with the grouping of scientific communications within existing journals. This question is very closely connected with that of the classification of science considered more particularly in the other Sections. It was recognized that the scatter of papers on essentially the same subject in journals is very wide ; but the 'working party' did not feel competent to indicate precisely how it should be reduced. It is suggested, however, that this could best be done by the setting up of standing consultative committees of editors in cognate subjects, as is already the case for the Biological Council. These 
editors might by negotiation arrange among themselves what subjects fell properly within the scope of the particular journal, and which might equally well ap. pear in a small number of journals. In the latter case some provision of exchange of lists of forthcoming papers might present the reader of any particular journal with information as to what is going on in his field far wider than he gets from the journals he can take and far more rapidly than he can get from ab. stracts. This 'working party' also considered the whole question of the formation of new journals or the extension and division of old ones. It concluded that the latter procedure is on the whole preferable, and that in any event it should not be penalized through the present control of paper supplies.

'Working party I/C' also dealt with two other questions of a more financial nature. It is clear that additional functions for editors, together with the responsibility of producing a paper in a better form (discussed above), would increase the work laid on them. It was recommended that means should be found to provide secretarial and other assistance to editors of journals, particularly smaller journals. The weak financial position of nearly all publishing bodies is clear from the proposal to extend the practice already prevalent in the United States of asking authors to pay for insertion of papers in journals ; this was supported by the 'working party' only in exceptional cases, while the Conference itself by a decisive vote was against requests for payment in any circumstances. This, of course, leaves the position exactly where it stands, and if rising costs are not to mean actual restriction of the amount published without regard to quality, the only solution can be through increased grants, either direct from Government or by some form of levy.

'Working party I/D' dealt with the very wide ques. tion of organisation of publication of original papers and mechanisms for their distribution. It was originally thought that this working party would deal with the detailed proposals of Prof. Bernal on reprint circulation; but as he himself (as he explained), in the light of the questionnaire on the subject, considered that distribution through libraries is far more important than distribution to individual research workers, this did not come up for discussion. Instead the "working party' concentrated on the means of obtaining separates directly from publishing bodies or by subsequent copying. The resolution as finally passed by the Conference, after emphasizing the importance of separates to scientific workers, called for a special exploration of the possibility of societies, libraries or commercial enterprises acting as agents for obtaining and distributing such separates. The question of copying separates, which is widely practised in individual cases, came up under the general question of copyright, at a special discussion at the Conference. 'Working party I/D' also emphasized the importance of library and information services, and particularly stressed the need for immediate Government action to provide for the enlargement of central scientific libraries and information services, and for providing for the effective functioning of these by an adequate staff having special qualifications in librarianship and science. It here made special reference to the Patent Office Library, the space in which has not been increased for many years, and to the Science Library. To increase the effectiveness of libraries it also proposed that library committees should co-operate to a greater extent than at present to prevent duplication.
'Working party I/E' had the task of exploring delays in publication and the availability of already published scientific material. It came to the conclusion that the best way of eliminating the former was by closer co-operation between the printing trades and the scientific societies, and in a resolution called on the Royal Society to organise a permanent liaison committee between industry and scientific publishing bodies. The technical means of more rapid publica. tion by alternative methods, particularly lithography, were discussed and the matter referred to a proposed standing committee on the development of reproductive methods (referred to below). Another point stressed by this 'working party' and incorporated in the general resolution of Section 1 was the need to increase the speed of every stage of the process of the production of a scientific paper, beginning with its actual writing, and passing through its examination by heads of departments, its refereeing and the various stages of actual reproduction and correction. Delay at any stage was felt to have a psychological effect, increasing the probability of delay at other stages. As to availability, particularly in the Commonwealth, this matter was felt to be very largely one of discovery of the whereabouts of the material, and therefore depended on indexing and abstracting. Here proposals for the preparation of lists of titles and abstracts, particularly those emanating from Domin. ions and Colonies, were made and incorporated in other resolutions of the Conference.

In the general meetings of the Section many points were raised by different 'working parties' so inter. related as to make it desirable to include them in one general resolution. It was proposed that the Royal Society should initiate a vigorous and sustained campaign to improve the preparation and presenta. tion of papers. This would involve action all along the chain of preparation, beginning with the research worker himself, who should be better trained than at present in the technique of writing and preparation of papers for publication. In turn, directors of research might be able to save very much editorial time and trouble at a later stage by careful preediting. Editors themselves, or the publication committees of their journals, were urged to take a more severe line than at present on the acceptance of papers for publication, eliminating so far as possible those that were merely repetitions with variations of papers appearing elsewhere, or those lacking in brevity or clarity of expression.

The recommendations of the 'working parties' were communicated to the plenary session of the Section on June 29, where they were subjected to lively but on the whole friendly discussion. They were for the most part, after certain amendments, accepted by the Conference as a whole, the only point of dispute being the question of the proposed précis-journals which, being a relatively new idea, certain of the delegates would have preferred to be omitted altogether from the resolution.

The full bearing of the recommendations of Section 1 can only be fully appreciated in relation to the general work of the Conference; but it may be claimed that although no radical changes were proposed, the sectional recommendations indicate in a precise manner what should be done by other bodies to improve the production and distribution of original scientific material. The technical questions were appropriately referred to representative committees which have some reasonable chance of getting their recommendations accepted. On the more 
general issues of improved distribution of reprints and a more concentrated and more rational grouping of papers in journals, much will depend on how far it is possible in practice to set up effective working committees of editors who, with the greatest know. ledge of their respective subjects, will be most able to set their particular house in order. It is to be hoped that members of scientific societies will also, as a result of the Conference, take more interest than they have in the past in the mechanism of publication, realizing that it is in their own hands to modify, and that it is not some divinely imposed order which they must accept without complaining.

\section{J. D. Bernat}

\section{Section 2: Abstracts and Abstract Journals}

On the shelves of the Athenæum Club is a series of annual volumes, politely styled, "The Works of the Learned". The date of the first is 1699. They are informative abstracts, longer than those now usual yet true to type. Abstracts of scientific papers are certainly not new. Yet the decision of the Royal Society to devote one main section of its Conference to the consideration of abstracts and abstracting services is likely to prove timely.

The keynote of the Conference was service to science and to the scientific worker. Abstracts exist to serve the scientist. That is their sole justification. The English-speaking peoples are the chief producers of scientific abstracts. The journals of some of the United Kingdom abstracting services have appeared without a break for more than seventy years. The number of those services has increased markedly in the last twenty to thirty years. Yet this Conference was the first occasion on which representatives of most of those services had met together as a group to consider how far they were serving the needs of science as a whole, how their methods and techniques agreed or differed and in what respects such variations detracted from extended use of their journals and labours. What also was most certainly new was to have available at such discussions the assistance and criticism of scientific workers of most varied interests and of representatives from the Dominions overseas, from the United States and from the United Nations Educational, Scientific and Cultural Organisation. This alone ought to make this Conference worth while in the long history of abstracts; but what was really surprising came out in the early days of preparation for the Conference, namely, the almost complete lack of factual information about the existing abstracting services, and of how scientific men, in their differing circumstances and in their different branches of science and its applications, actually used abstracts and for what purposes. Was their chief purpose to provide 'current awareness', making speed of issue the prime requisite and their useful 'life' comparatively short? Or were they often consulted over periods of five, ten or even twenty years, in which event obviously good subject indexes, and where possible consolidated five- or ten-year indexes, were a great advantage? Was it broadly true that while an informative abstract is invaluable to the scientific worker far from a good library, as one working in a Colony, the indicative type of abstract generally meets the needs of anyone in the United Kingdom? Precise answers to such questions must vary in different branches of science, but are enough facts known to afford any general guidance or lead to abstracting agencies as a whole?
Opinions were numerous on how abstracts should be written, how indexed, on their type, on their excellence in some cases and failures in others, on their 'gaps' and 'overlaps' and on the difficulties in borderline subjects; but facts were few. This was inevitable, for surprising though it may seem, no list of the abstract journals published in the United Kingdom was readily available; consequently, no ready information on the branches of science and of its applications they, as a whole, presumed to cover. It is not suggested that any scientific men could or would have occasion to refer to all the abstracting journals. He knows one or two, and may at times be referred by his librarian to others; but if no ready information of their general coverage is available, he can scarcely be expected to refer to a journal the title of which may be vaguely familiar to him although he may be ignorant of its scope. The plight of a scientific man overseas wishing to use United Kingdom abstracts is greater.

Factual information had been collected from many of the abstracting agencies. This was presented to the Conference in condensed form, also the results of some inquiries into the use of abstracts. The Conference, however, realized broadly how the present services had grown up, their general character, the experience gained and knowledge orderly accumulated. It referred the whole subject to three 'working parties'; one to examine the place of abstracts in the service of scientific workers, their relation to other forms of service, such as reviews, bibliographies, etc., and to review the existing services; a second composed mostly of representatives of the abstracting agencies to compare their methods, techniques and practices; and a third to look to the future.

A paper presented by the Science Library, London, showed that notices in abstracts probably cause most inquiries for copies of original papers (possibly a third of the total), closely followed by references to papers in other papers. Prof. J. D. Bernal's pilot survey in Cambridge and elsewhere placed it lower at one-sixth. A small-scale but very welcome voluntarily organised inquiry in the University of Birmingham showed a preference of more than three to one for informative abstracts, and that about onethird of new papers were discovered through abstracts. Other information suggested that informative abstracts were more used in the United Kingdom than might have been thought. But all these inquiries were on too small a scale to give any reliable indications. Also, to be useful, they would need to be broken down according to the different branches of science and its application. A diagrammatic representation of the inter-relations of science and the scope of existing abstract agencies which Dr. H. J. T. Ellingham had prepared showed at a glance present gaps and overlaps. Gaps, time-lag and indexing were the chief subjects of complaint.

One fairly recent change in the type of user came out, arising from the extended use of science in organised industry. This is the increased reliance of many scientific workers on the 'information officer' for help in searching and in obtaining literature. The information officer thereby becomes another and constant user of abstract journals. Also, such are the extensions of the use of science in industry that many abstracting agencies may not have included these officers as users of their journals. Abstracts have always been designed to serve particular groups of scientific workers directly, and the various abstracting services look on their work from that angle; but as 
this tendency extends, consideration of the needs of these information officers as potential users of their journals becomes important.

As regards the abstracting services, the facts collected brought out several points. Most of the published abstracts are of the informative, that is, longer, more detailed, type. British Abstracts, the largest single service, are of the brief, or indicative kind. Nearly all are on a non-profit earning basis. This means that behind each is some sponsor society or department. It thus follows that the phrase 'abstracting agencies or services' cloaks many varia. tions of functions or duties. The functions of any agency are those laid down or approved by its sponsor society or department. These may be confined to the preparation and issue of abstracts, as with World Abstracts of Medicine; or, as with the Tropical Diseases Bureau and the Commonwealth Agricultural Bureaux, they may be those of centres of information entailing aid in preparing reviews, in obtaining reprints or copies of papers, or translations or even in identifications. The issue of the abstract journal then becomes one of several duties and not a sole function. The agencies are not thus all of one type or origin, capable of easy recasting or reshuffling. They differ in function, type, scope and finance. But they all have this basal characteristic in common : each has been called into being at the instance of scientific men, engaged in some branch of science or of its application, to serve their particular needs; each is responsible to (and ultimately controlled by) scientific men in its sponsor society or department.

In each case responsibility for the abstract journal rests on scientific workers trained in that subject. Control may become difficult in particular cases; but the identification of a service with those engaged in a particular branch of science or of its application should foster service of a type suitable to its needs and the maintenance of quality and accuracy. This identification of a service with a particular group carries a corollary. The primary loyalty or allegiance of any abstracting agency is to the scientific workers in its sponsor society or department. The Conference showed no desire to disrupt such associations, or to subject them to outside authority, for the sake of a general uniformity. To have done so would have been to ignore differences between the needs of different branches of science, and the fact that in some agencies overseas interests are active participants; yet an indefinite increase in the number of isolated independent services must lead, in the ever-increasing inter-relationships of science, to overlapping and confusion rather than to clarification. Responsibility to a particular group or branch is in no way incompatible with better service to science as a whole. The operative portions of the Conference's terms of reference to the third working party, that looking to the future, were then : "To consider and report, with recommendations if desired, on the advisability, cost, organisation and functions for a Council on Abstracting, not to centralize all abstracting, but as a continuing agency, to promote co-operation between abstracting services, the elimination of gaps . . ."

It was with this background of facts and ideas that the 'working parties' started on their labours. It was impossible in the few days at their disposal to solve definitely all the points which arose. This was especially so in the second 'working party' where, for the first time, abstracting agencies had met to examine their methods. Differences undoubtedly existed. To adjust those so as to secure a wider use of their journals is a continuing task and not one to be settled in a few preliminary meetings. They therefore presented their findings to the Conference chiefly in the form of conclusions, rather than recommendations. The first 'working party' also presented most of its findings by way of conclusions. The conclusions and recommendations were placed later before the Conference, were discussed, passed, amended, or rejected by it. The leaders of the three 'working parties' were Dr. H. G. Thornton, Mr. B. Fullman, and Dr. G. M. Findlay; the recorders Dr. M. A. Vernon, Mr. J. Beak and Dr. B. M. Crowther. All 'working parties' had the help of representatives from the countries overseas and from the United States. Mr. J. B. Reid, of the United Nations Educational, Scientific and Cultural Organisation, brought to Working Party No. 3, looking to the future, the latest information on international developments.

The conclusions reached by the Conference should, if followed, improve the general usefulness of abstracts. A few only can be mentioned here. Some overlapping between abstract services is desirable, when the services cater for readers having different interests. Such overlap is distinet from duplication. For this reason a single set of abstracts produced by a central agency would not suffice for universal use. Publication of abstract journals, covering identical fields and directed to the same type of user, constitutes duplica. tion and is to be deplored. The quality of abstract indexes is frequently unsatisfactory. Abstracting services, unless combined with an information service, as is often desirable, cannot be expected to answer specific inquiries on literature. By way of comment on this point, it may be explained that this conclusion merely reflects the differing functions of these services, as already explained. All realized that the usefulness of abstracts is gravely impaired if the means for obtaining copies of the original papers are inadequate. This question kept reappearing in all sections of the Conference, and is undoubtedly one of prime importance.

Among the recommendations was a strong emphasis on the need for comprehensive subject indexes to be provided with each volume; and a recommendation that consolidated subject indexes be provided at intervals. But the chief recommendation adopted by the Conference was that on co-operation in the future. It was to the effect that the Royal Society be invited to consult the abstracting agencies to set up a standing consultative committee of abstracting organisations for mutual exchange of views and generally to promote co-operation. The Committee should consist of representatives of bodies responsible for the production of journals of abstracts. It should work on a voluntary basis and the cost be kept low. Among earlier matters for its attention were listed, increasing uniformity in the services in the methods of bibliographical citation, the maintenance of a comprehensive list of journals of abstracts, the question of its publication and the possibility of including in it an indication of the general scope of each journal, the possibility of co-ordination of systems of indexing, the determination of fields where readers' needs are inadequately met, and the maintenance of a panel of abstractors with special linguistic knowledge.

If this standing committee is formed-and all the main abstracting services were in favour of it-many questions besides those tabulated will come before it, 
though those when worked out should greatly extend the knowledge and usefulness of abstracts. Not only will this be the first time that these agencies have met to exchange information and experience, but also such meetings and consultations will have a definite object, namely, to promote co-operation in the service of science generally. An aim has been given. This recommendation may thus become among the most constructive from the Conference in this Section. It is certainly timely, in the light of the increase in the number of these services, the increased efforts in applying science, the general stir for better organised dissemination of information and the revived interest of the possibilities of co-operation on the international level. On this the Conference, while recognizing the difficulties, urged organisations covering similar fields to make efforts at closer collaboration.

The conclusions and recommendations of the Conference in this matter of abstracts may not seem so wide or so drastic as some might have wished; but though much testimony was given to the utility of present services, the striking characteristic of the Conference was this-no question was approached from a particularist point of view. The obvious desire of all was to secure better service to the scientific worker; to build on what had been learnt, but to harmonize and adapt it so as to be even more effective in the service of science. The long history of abstracts to meet the needs of science is not closed-perhaps, indeed, a new phase is opening; the particular services will continue, for the needs of scientific men in different branches and in different circumstances must vary. But while preserving all that is most useful in that respect, conscious collab. oration in the interest of science as a whole will constantly grow, so that the journals become more widely known, more easily used, borderline cases provided for, and needless diversities of practice eliminated.

In all this the visitors from overseas played an active and stimulating part. When discussing abstracting, the needs arising from one's own local conditions and circumstances are apt to be so prominently and even fatally in one's mind as to distort the conception of what must be in some degree a general and not an individual service. The overseas delegates helped to keep this needed balance.

David Chadwick

\section{Section 3: Indexing and other Library Services}

Whereas Section 2 of the Conference was concerned in securing awareness of current publications, Section 3 dealt with the provision for retrospective searching : the problem of how to dispose literature references in such a way that those among them which may help to satisfy any particular quest for information liable to arise in the future will be turned up, when the time comes, with certainty and speed.

This problem includes what is normally understood by librarianship, and also goes far beyond it in magnitude and complexity. A librarian in the traditional sense is occupied with the procurement, store-keeping and cataloguing of books as complete units; but not with analysing their contents or indicating their relevance. Yet a single book, journal article or patent specification may touch on many subjects and be important from many points of view; and the mere fact that a library which holds a copy of it has catalogued it under its author and title, or even under such multiple subjects as may be implicit in the title, goes only a very little way towards what is required. The problem of documentation is, in fact, to ensure that when a scientific man needs to find out what has already been done and thought regarding any topic whatever, he can quickly be given the most apposite references not only among the hundreds of thousands collected in his own departmental library but also among the millions available to him, by way of loan or photo copy, from the libraries of the world at large.

Any one of these may turn out to be the one which would best serve the interests of some future inquirer, if only he knew of its existence, by enabling him to begin his own researches from a more advanced starting point. There being no means, however, of foreseeing which item that will be, there are needed economical techniques for the mass processing of the greatest possible range of literature references to meet the contingency that any one of them may be of value. Fundamentally, there are four ways, each with its variations and its advantages and disadvantages, along which this central problem can be attacked :

(1) Indexing the names of subjects in alphabetical order. This is the usual system in books and at the end of each year's run of a journal; under certain conditions it is satisfactory also for card indexing. But it involves many more difficulties and moot points than are apparent at first sight. It has the effect of dispersing logically contiguous items according to the letters of the alphabet with which their names happen to begin, and as the names are not standardized so as to make them mutually exclusive, a searcher is liable to look in vain for something which the indexer has buried elsewhere under a synonym.

(2) Classifying the subjects themselves under symbols which serve to pinpoint their positions in a logically constructed map of knowledge. Many such classifications are in use, some locally for special fields of subject-matter and some general like the Universal Decimal Classification, which is an internationally standardized extension of the Dewey system developed by librarians for shelving books. On this system, knowledge as a whole is divided into ten primary branches each denoted by a first decimal number, each of these into ten subdivisions denoted by a second decimal, each of the latter into ten sub-subdivisions denoted by a third decimal, and so on to whatever degree of particularization is required. As the sequence of subjects is ideographic, not alphabetic, an alphabetically arranged key (corresponding to the gazetteer in an atlas) is necessary for locating subjects when only their names are known.

(3) Coding the subjects under symbols which can be represented by patterns of holes punched in a card, or by patterns of dots detectable by optical means alongside a microfilm of the document under reference. Items so coded can be stored in random order and run through a machine, when required, which automatically picks out those of them which have been coded in any particular way.

(4) Coding the shapes of certain classes of objects under symbols which can be treated as above. The Dyson and the Gordon-Kendall-Davison systems of chemical notation enable this to be done for the arrangement of atoms in a complex molecule, which makes possible the mechanical selection of references to chemical compounds according to their molecular structures. 
As staff and resources for bibliographical work are limited, the application of any of these methods must be governed by a proper balance of time and effort between indexing or classification on one hand and searching on the other. The greater the chance of references of a given kind being of future interest, the greater the justification for the labour of analysing them minutely and of consolidating those of different dates and sources into a single cumulative index. Where, however, a subject is unlikely or seldom likely to be of interest, it is more economic to rely on making an ad hoc search if and when the occasion for it arises, even though this may involve the tedious job of consulting the separate annually published indexes of many separate journals in which references might be found. Elaboration of indexing is, in fact, an insurance, and just how big a premium it is worth must depend on circumstances.

Two of the working parties in Section 3, dealing respectively with classification and with mechanical methods, drafted recommendations which the Conference adopted on various practical aspects of this central problem.

The Universal Decimal Classification, it was held, has both advantages and limitations. Among its assets are the millions of existing references so classified and the many thousands being published every year with the class numbers already printed on them; these are among the justifications for continued extension in its use. But the criticisms to which it stands exposed were recognized also and led the Conference to favour setting up a standing committee for fundamental research into subject classification of science without pre-commitment to any particular system. Further study and research on alphabetical arrangement were also recom. mended.

Similarly a full-scale experiment on mechanical methods of selection was urged, as well as encouragement of the Aslib committee which is studying and collating progress in this field. A particular device, exhibited at the Conference, which the working party found of interest though no positive recommendations was made about it at this stage, was the invention of Dr. J. Samain of Paris: this has a typewriter-like keyboard whereby up to 24 six-letter words can be punched directly in a single card, and a selector able to pick out those cards which carry any desired word or combination of words regardless of the position or sequence in which these occur on particular cards.

On the question of chemical notation suitable for punching on cards, the Conference recommended that the attention which appropriate bodies are giving to one system be extended also to others proposed.

Another working party studied photographic and other new methods of reproduction. These have many important uses in bibliographical work, and the Conference recommended the establishment of an advisory committee to stimulate and watch developments in Great Britain and in other countries. As an example, it is an obvious economy if index items or abstracts which are required to be circulated sequentially in page form and also to be cumulated separately in card form can bə reproduced in both forms without having to typeset or typewrite them (and check them) twice over. In the United States this is now widely practised. Another recommendation of the Conference which depends for its economy on suitable methods of reproduction was the issue from a central source of guide cards bearing Universal Decimal Classification numbers, for insertion direct into card indexes instead of having to copy them locally from a list. Again, in the United States the Library of Congress issues printed catalogue cards for all the books it handles, which hundreds of other libraries can use instead of having to do the work over again locally. Steps to develop such a service in Great Britain were recommended.

Among the new methods of reproduction studied and commended by the Conference was a Dutch process of diazo-printing (much cheaper than photography using silver chemicals) which enables not only direct copying from single-sided translucent originals but also, by a reflex method, copying from doublesided or opaque originals including the pages of bound books. This system has the further immense advantage that processing of the exposed paper is dry (or practically so) and therefore instantaneous, so that one or many copies of any document can be obtained, as and when required, in an ordinary office.

Various questions affecting the use of microphotography were studied, including the supersession of continuous lengths of film by strips or other more convenient units. Apart, however, from technical points like this, the great possibilities latent both in microphotography and in full-sized photo-copying for assisting the dissemination of scientific literature are governed more than anything else by restrictions resulting from the present copyright law. To give only one instance: if these could be removed by legislative reform, or circumvented by some form of agreement with authors' or publishers' organisations, the production and distribution of separate offprints of articles printed in journals would be greatly facilitated. The copyright question was discussed by the Conference at considerable length, and a recom. mendation was put forward stating the necessity for the provision of single copies of extracts from books and periodicals for purposes of scientific research and inviting the Royal Society to initiate action in the matter.

A fifth working party, which considered data tables, reference books and guides to information services, compiled a useful bibliography of these works. The Conference recommended continued action to ensure that scientific compendia in all fields of science were available and up to date, and to assist their publication where necessary. Financial aid to speed a new edition of the "ASLIB Directory" was urged, and a hope expressed that the "World List of Scientific Periodicals" might be re-issued as early as possible. The Conference recommended compilation of a British work corresponding to "Industrial Research Laboratories in the United States and Canada", and also of a subject index to the research activities and specialized knowledge of individual men of science.

Some 40 per cent of the world's scientific publications are in languages other than English; hence the importance of the questions referred to the sixth working party of Section 3, which considered translation services. As a result of its labours the Conference recommended greatly increased publicity for the ASLIB Register of Specialist Translators, which enrols only persons who combine linguistic knowledge with knowledge of particular branches of scientific or technical work; also its extension to those qualified to act as interpreters, by the simultaneous method, at international scientific conferences. Other recom. 
mendations included the institution of university or other suitable diplomas in translating and interpreting, the establishment of a central location index to unpublished translations, and that the Government be asked to consider action to modify the Berne Convention on international copyright so as to allow organisations such as the Science Museum Library to make available any translations deposited with them.

\section{J. E. Holmstrom}

\section{Section 4: Reviews and Annual Reports}

Reviews of a critical and constructive nature, written by leaders in particular branches of science, are of the greatest value, and senior investigators should regard the production of these as an important ancillary to the pursuit of new knowledge. The fields covered by critical reviews depend upon the first-class reviewers available at any given time. Such reviews, written by specialists, can be made very informative to workers in allied fields by the inclusion of an introduction and conclusion of a general, and as far as possible non-technical, nature. The desirability of the inclusion of the titles of papers in the bibliography of reviews and other scientific papers varies with the science; it is desirable in biology, possibly less so in chemistry.

Annual or biennial reviews, progress reports and books on recent advances serve a useful purpose, especially if prepared as critical reviews rather than synoptic summaries. Reviews written by specialists for workers in other branches of science are of great importance and at present are insufficient. In the applied sciences there is also a need for more review publications. In this connexion considerable material could perhaps be made available for publication by the larger industrial concerns.

Reports on 'symposia' are recognized as a valuable contribution to the recording of progress in science but are not a substitute for reviews or annual reports. A wider distribution of copies of the more important review lectures is desirable.

H. MUNRO Fox

\section{THE PALESTINE FLORA}

\section{BY ERIC HARDY}

$\mathrm{T}$ HE trouble in Palestine sets back the clock on the recent efforts of both Arab and Jewish gardeners to develop the horticultural attractions of the Holy Land, for the palm boulevards of Jaffa, and the flower-growing settlements at MishmarHasharon, etc., had attracted much praise and attention. The danger, however, goes deeper, for modern Palestine was not the primitive wilderness of brigand and bedouin as depicted in most of the Western religious books. Several excellent gardens and plant collections were in the country, and their future is threatened by the bittermess of war. There is, for example, the best of the attempts to create a typically English garden, with its lawns and roses, its rockery and its pergola, which was in the grounds of Government House on the dry and dusty hill outside Jerusalem. On besieged Mount Scopus the botanical department of the University of Jerusalem housed the finest herbarium of the Near East flora, with more than 300,000 sheets of specimens collected not only in Palestine, but also in Syria, Arabia, Transjordan, and in particular the desert regions.
There was also the private collection of Palestine and Transjordan plants collected in the American Colony in Jerusalem by J. E. Dinsmore, editor of the second edition of Post's "Flora of Palestine and Syria", where also the garden of a score of varieties of Palestine irises was a famous feature in April. Another internationally famous private herbarium, the largest outside the University, is the Herbarium Boyko, housed at the village of Talpioth, between Jerusalem and Bethlehem, in the home of Dr. Hugo Boyko, its compiler, an official of the Mandatory Government's Department of Forests.

At Rehovoth, which has been subject to several air raids, are housed the laboratories, collections, trial gardens, etc., of the country's main horticultural research. Here Dr. Oppenheimer, Dr. Samech and others maintained the vast organisation of the citrus research and the fruit-growing industry, where East Malling ideas were developed and plants acclimatized and tested. The horticultural edition of the Palestine Journal of Botany is produced here under Dr. Oppenheimer's editorship, while the purely botanical edition is produced at the University of Jerusalem under Prof. Zohary's editorship.

In recent years the University of Jerusalem had established a botanic garden on Mount Scopus, mainly for shrubs and trees typical of the country's flora, and including a coppice of cedar of Lebanon. Under the Mandatory Government, the Departments of Forests and Agriculture maintained several sta. tions existing from Turkish times, like the vineyards, date palms and orchards at the old Turkish horticul. tural station in Jericho, and they established others. Near Acre the Mandatory Government established its main stock farm and horticultural and field crop station; its station for deciduous trees, carobs, vines and pruning instruction was near Safad. At Farawana, near Beisan, in the middle Jordan Valley, it had a station for sub-tropicals, olives, vines and dates; another near the historic Jacob's Well at Nablus for olives, vines and pomegranates; an experimental station for miscellaneous work was at Majdel, and a forestry station at Gaza that has been plant. ing a large acreage of wind-blown sand with tam. arisk to check the inroads of the Sinai sandstorms. From these stations, Arab gardeners were taught Western ideas of grafting and pruning, particularly for olive cultivation. The famous Arab olive orchards at Beit Jala near Bethlehem, and their pomegranate orchards near Ramallah, were a tribute to the work.

On the cool and fertile shores of southern Galilee, the Jews maintained a remarkably interesting nature study and agricultural institute called Beth Gordon, in memory of a pioneer settler, Aaron Gordon. This was at Degania settlement, in the vicinity of much of the recent fighting between Tiberias Jews and the Iraqi Army. Beth Gordon (or Gordon House) was open to any visitors interested in natural history or horticulture irrespective of membership. It main. tained laboratories, lectures, a card-indexed library of 12,400 books in several languages, a museum with 18,500 animal specimens and a herbarium of 3,400 named plants, all under the direction of M. J. Palmoni. This was mainly a teaching centre, whereas Rehovoth was the main centre of horticultural research and plant acclimatization.

For several years the European colony in Jerusalem maintained a Jerusalem Horticultural Society, and in 1928 it published an instructive little booklet on the cultivation of gardens under those high, dry, chalky 